Original Article

Journal of National Institute of Neurosciences Bangladesh,

January 2020, Vol. 6, No. 1, pp. 29-32

ISSN (Online) 2518-6612

ISSN (Print) 2410-8030

\title{
Histopathological Diagnosis of Colposcopically Negative Cases for CIN
}

\author{
Khurshida Samad ${ }^{1}$, AJE Nahar Rahman², Imtiaz Ahmed ${ }^{3}$, Abu Sayeed Mohammad, \\ Md. Sirajul Islam ${ }^{5}$ \\ ${ }^{1}$ Assistant Professor, Department of Pathology, National Institute of Ophthalmology \& Hospital, Dhaka, Bangladesh; \\ ${ }^{2}$ Professor, Department of Pathology, Bangladesh Institute of Research and Rehabilitation in Diabetes, Endocrine and \\ Metabolic Disorders, Dhaka, Bangladesh; ${ }^{3}$ Associate Professor, Department of Microbiology, Col. Malek Medical \\ College, Manikgonj, Bangladesh; ${ }^{4}$ Associate Professor, Department of Dermatology \& Venereology, Mugda \\ Medical College, Dhaka, Bangladesh; ${ }^{5}$ Assistant Professor, Department of Critical Care Medicine, National \\ Institute of Neurosciences \& Hospital, Dhaka, Bangladesh
}

[Received: 12 November 2019; Accepted: 2 December 2019; Published: 1 January 2020]

\begin{abstract}
Background: Colposcopy is a good diagnostic tools for the detection of abnormalities cervix of the uterus. Objective: The purpose of the present study was to see the histological diagnosis of colposcopically negative cases for CIN among VIA positive women. Methodology: This cross sectional study was conducted in the Department Of Pathology at Bangabandhu Sheikh Mujib Medical University (BSMMU), Dhaka, Bangladesh during the period of July 2007 to June 2008 for one (01) year. Patients who are colposcopically negative but clinically suspicious for cervical neoplasia were included in this study. The cervix was examined on naked eye by Cusco's speculum to see whether it was healthy or not. Then it was examined by the colposcope after applying 3 to $5 \%$ acetic acid and colposcopic findings were collected. VIA positive cases were underwent colposcopy guided LEEP biopsy. Result: A total of 63 patients of different age group were recruited for this study. The age of 63 patients ranged from 20 years to 65 years with an average age of $34.6 \pm 9.59$ years. Among 63 VIA positive patients, 54 cases were colposcopically positive for cervical intraepithelial neoplasia and carcinoma in situ, remaining 9 patients were colposcopically negative. Histological examination was also performed in nine patients who were colposcopically negative but clinically suspicious for malignancy or precancerous lesion. Of these nine cases, eight cases $(89 \%)$ were diagnosed as chronic cervicitis, one case $(11.0 \%)$ as CIN-I and none as CIN-II and CIN- III. Conclusion: In conclusion majority of the colposcopically negative VIA positive cases are the patients of chronic cervicitis. [Journal of National Institute of Neurosciences Bangladesh, 2020;6(1): 29-32]
\end{abstract}

Keywords: : Histopathological diagnosis; colposcopically; negative cases; CIN

Correspondence: Dr. Khurshida Samad, Assistant Professor, Department of Pathology, National Institute of Ophthalmology Hospital, Sher E Bangla Nagar, Dhaka, Bangladesh; Cell no.: +8801552421396; Email: khurshidarmc@gmail.com

Conflict of interest: There is no financial conflict of interest relevant to this paper to disclose.

Funding agency: This project was not funded by any group, organization or institution.

Contribution to authors: Samad K, Rahman AJEN, Ahmed I were involved in concept and design of the study; however, Samad K \& Rahman AJEN were involved in data collection, data compilation, processing and analysis, while in addition to Mohammad AS, Islam MS were equally involved in the literature search, compilation, manuscript writing and revision.

How to cite this article: Samad K, Rahman AJEN, Ahmed I, Mohammad AS, Islam MS. Histopathological Diagnosis of Colposcopically Negative Cases for CIN. J Natl Inst Neurosci Bangladesh, 2020;6(1): 29-32

Copyright: (C2020. Samad et al. Published by Journal of National Institute of Neurosciences Bangladesh. This article is published under the Creative Commons CC BY-NC License (https://creativecommons.org/licenses/by-nc/4.0/). This license permits use, distribution and reproduction in any medium, provided the original work is properly cited, and is not used for commercial purposes.

\section{Introduction}

Cervical cancer is the commonest cancer among women in Bangladesh ${ }^{1}$. It is about $24.0 \%$ of all cancer in females ${ }^{2}$. Most cervical cancers are diagnosed at the advanced stage; thus, mortality is high. Among the cancers, cervical cancer is a preventable disease. This is based on the postulation that the development of cervical intraepithelial neoplasia (CIN) is a continuum which begins with less atypical and less extensive lesion and progress to a malignant lesion over a period of several years ${ }^{3}$. Thus, if the process can be treated at the onset, the development of invasive cancer can be prevented and that reduce the rate of mortality. 
Cervical cancer arises from earlier, reversible precursor lesions called cervical intraepithelial neoplasia ${ }^{4}$. The lesion may exist in the noninvasive stage as long as 20 years and shed abnormal cells that can be detected on cytologic examination ${ }^{5}$. That is the reason why Papanicolaou smear (Pap smear) screening is very effective in preventing cervical cancer as majorities of cancer are preceded by a precancerous lesions ${ }^{6}$. However, the Pap smear has several limitations; furthermore, to interpret the Pap smear requires skilled pathologist specially cytopathologist.

In Bangladesh, cytopathologists are few in number. Most Pap smear abnormality which do not signify a serious precancerous or cancerous condition, require lengthy follow up procedure and large number of patients are lost in this process ${ }^{7}$. This present study was undertaken to see the histological diagnosis of colposcopically negative cases for CIN among VIA positive women.

\section{Methodology}

The descriptive cross sectional study was carried out in the Department Of Pathology at Bangabandhu Sheikh Mulib Medical University (BSMMU), Dhaka, Bangladesh during the period of July 2007 to June 2008 for one (01) year. All the cases were selected from cervical cancer screening program based on VIA (visual inspection of cervix with acetic acid) test founded by United Nation Population Fund and Government of Bangladesh (GOB) in the Department of Gynaecology and Obstetrics, BSMMU, Dhaka. VIA test is done with 3 to $5 \%$ acetic acid. VIA positive cases underwent colposcopy guided LEEP biopsy. Patients who were colposcopically positive for cervical intraepithelial neoplasia and early invasive carcinoma or patients who are colposcopically negative but clinically suspicious for cervical neoplasia were included in this study. Menstruating women or $\mathrm{P} / \mathrm{V}$ bleeding present during the time of examination, obvious clinically malignant growth at the cervix, patient below 18 years of age and unmarried women were excluded from this study. The clinical history was obtained by taking history with particular attention to age, age at marriage, parity, history of contraceptives, abnormal per vaginal discharge and post coital bleeding. The cervix was examined on naked eye by Cusco's speculum to see whether it was healthy or not. Then it was examined by the colposcope after applying 3 to $5 \%$ acetic acid and colposcopic findings were collected from colposcopy unit in the Department of Gynaecology and Obstetrics at BSMMU, Dhaka. The colposcopic examination was carried out as an outpatient procedure. Then the colposcopy guided LEEP biopsy was performed in only VIA positive women using the video colposcopy.

\section{Results}

A total of 63 patients of different age group were recruited for this study. The age of 63 patients ranged from 20 years to 65 years with an average age of $34.6 \pm 9.59$ years. Majority of the women were in the age group of less than 40 years which was $51(81.0 \%)$ cases and the rest $12(19.0 \%)$ cases were in the age group of more than or equal to 40 years (Table 1).

Table 1: Age Distribution among the Study Population ( $\mathrm{n}=63$ )

\begin{tabular}{lcc}
\hline Age Group & Frequency & Percent \\
\hline$<40$ Years & 51 & 81.0 \\
$\geq 40$ years & 12 & 19.0 \\
Total & $\mathbf{6 3}$ & $\mathbf{1 0 0 . 0}$ \\
Mean \pm SD (Range) & $34.6 \pm 9.59$ (20 to 65 years) \\
\hline
\end{tabular}

Among 63 VIA positive patients who underwent colposcopic examination, 54 cases were colposcopically positive for cervical intraepithelial neoplasia and carcinoma in situ, remaining nine patients were colposcopically negative but their history and clinical findings were suggestive of neoplastic change (Table 2).

Table 2: Findings of colposcopic examination $(n=63)$

\begin{tabular}{lcc}
\hline Colposcopic findings & Frequency & Percent \\
\hline Positive & 54 & 85.7 \\
Negative & 9 & 14.3 \\
Total & $\mathbf{6 3}$ & $\mathbf{1 0 0 . 0}$ \\
\hline
\end{tabular}

Colposcopically 54 cases were divided in different grades of CIN and cancer. Among these 29 cases (53.7\%) were CIN-I, 21 cases $(38.8 \%)$ were CIN-II, three cases $(5.5 \%)$ were CIN-III and one case $(1.8 \%)$ was carcinoma in situ (CIS) (Table 3).

Table 3: Distribution of CIN among Colposcopic Positive Cases $(\mathrm{n}=54)$

\begin{tabular}{lcc}
\hline Colposcopic findings & Frequency & Percent \\
\hline CIN I & 29 & 53.7 \\
CIN II & 21 & 38.9 \\
CIN III & 3 & 5.5 \\
CIN IV & 1 & 1.9 \\
Total & $\mathbf{5 4}$ & $\mathbf{1 0 0 . 0}$ \\
\hline
\end{tabular}

Out of 63 cases, 20 cases were chronic cervicitis; 23 cases were CIN-I; 16 cases were CIN-II; 3 cases were CIN-III and 1 case was CIS. Colposcopically 29 cases 
Table 4: Comparative analysis between colposcopy and histopathology

\begin{tabular}{lcccccc}
\hline \multirow{2}{*}{$\begin{array}{l}\text { Colposcopic } \\
\text { Diagnosis }\end{array}$} & \multicolumn{3}{c}{ Histological Diagnosis } & Total \\
\cline { 2 - 5 } & No CIN & CIN-I & CIN-II & CIN-III & CIS & \\
\hline No CIN & $8(88.8 \%)$ & $1(11.1 \%)$ & $0(0.0 \%)$ & $0(0.0 \%)$ & $0(00.0 \%)$ & 9 \\
CIN-I & $10(34.4 \%)$ & $18(62.1 \%)$ & $1(3.4 \%)$ & $0(0.0 \%)$ & $0(00.0 \%)$ & 29 \\
CIN-II & $2(9.40 \%)$ & $2(9.5 \%)$ & $16(76.1 \%)$ & $1(4.7 \%)$ & $0(00.0 \%)$ & 21 \\
CIN-III & $0(0.0 \%)$ & $0(0.0 \%)$ & $1(33.3 \%)$ & $2(66.6 \%)$ & $0(00.0 \%)$ & 3 \\
CIS & $0(0.0 \%)$ & $0(0.0 \%)$ & $0(0.0 \%)$ & $0(0.0 \%)$ & $1(100.0 \%)$ & 1 \\
Total & $\mathbf{2 0}$ & $\mathbf{2 1}$ & $\mathbf{1 8}$ & $\mathbf{3}$ & $\mathbf{1}$ & $\mathbf{6 3}$ \\
\hline
\end{tabular}

$\mathrm{CIS}=$ carcinoma in situ;

were diagnosed as CIN-I and among these cases 18 cases were CIN-I histologically, 10 cases were chronic cervicitis and 1 case was CIN - II. Thus, correlation of CIN-I was $62.1 \%$. All cases colposcopically diagnosed as CIN-II (21 cases), CIN- III (3 cases) and CIS (1 case) were confirmed by histology. Among these cases correlation of CIN-II, CIN-III and CIS were $76.1 \%$, $66.6 \%$ and $100.0 \%$ respectively (Table 4 ).

Histological examination was also performed in nine patients who were colposcopically negative but clinically suspicious for malignancy or precancerous lesion. Of these nine cases, eight cases (89\%) were diagnosed as chronic cervicitis, one case $(11.0 \%)$ as CIN-I and none as CIN-II and CIN- III (Table 5).

Table 5: Histological diagnosis of colposcopic negative cases $(\mathrm{n}=9)$

\begin{tabular}{lcc}
\hline Histological diagnosis & Frequency & Percent \\
\hline Chronic cervicitis & 8 & 88.9 \\
CIN I & 1 & 11.1 \\
CIN II & 0 & 0.0 \\
CIN III & 0 & 0.0 \\
CIN IV & 0 & 0.0 \\
Total & $\mathbf{9}$ & $\mathbf{1 0 0 . 0}$ \\
\hline
\end{tabular}

\section{Discussion}

The current understanding of cervical cancer arises from earlier, reversible precursor lesion called cervical intraepithelial neoplasia ${ }^{8}$. The lesion may exist in the noninvasive stage as long as 20 years and shed abnormal cells that can be detected on cytological examination'. The reason that papanicolaou smear screening is so effective in preventing cervical cancer is that majority of cancer are preceded by a precancerous lesion ${ }^{10}$. On the other hand in developing countries, it is attempted to prevent cervical cancer through VIA test. Current advances in understanding of the cause and natural to history of cervical neoplasia and in particular the establishment of the central role of human papilloma virus, a sexually transmitted agent that infect cells of the cervix and slowly cause cellular change (dysplasia) that can result in cancer ${ }^{11-13}$.

A total of 63 cases were included in this study. These cases were selected after clinical examination, visual inspection with acetic acid (VIA) test and colposcopic examination. Only VIA positive cases were selected for colposcopy. Among 63 ceases. 54 cases were colposcopically positive and nine cases were colposcopically negative but clinically suspicious. In the present study age ranged from 20 to 65 years with an average age of $34.6 \pm 9.59$ years. Majority of the women are in the age group of less than 40 years which is $51(81.0 \%)$ cases and the rest $12(19.0 \%)$ cases are in the age group of more than or equal to 40 years. Similar result has been reported by Ashrafunnessa et $\mathrm{al}^{2}$.

In this study on histopathological examination of 54 colposcpically positive cases $41(75.92 \%)$ cases were diagnosed as cervical intraepithelial neoplasia (CIN); furthermore, 1 case was carcinoma in situ (CIS) and 12 $(22.2 \%)$ cases were chronic cervicitis. Among the CIN lesions, 22(40.7\%) cases were CIN I, 16 (29.6\%) cases ere CIN II, three $(5.5 \%)$ cases were CIN III. Colposcopically negative but clinically suspicious 9 cases were histologically diagnosed as chronic cervicitis in $8(89 \%)$ cases and only 1 case was CIN I. Among the colposcopically positive cases $(n=54), 29$ cases were CIN I; 21 cases were CIN II; 3 cases were CIN III and 1 case was carcinoma in situ (CIS). Thus, correlation between colposcopy and histology was $68.25 \%$ ) which was less than the study by Seshasdri et al $1^{4}$ where the correlation was $78.9 \%$ but more than the study by Amin $1{ }^{5}$ where the correlation was $63.7 \%$.

Human papilloma virus (HPV) is the major etiological agent of cervical cancer. HPV infection of the cervix is transmitted venerally and it has a predilection for the metaplastic squamous epithelium. The morphologic hallmarks of HPV infection of the cervical epithelium is koilocytosis or koilocytic atypia. Koilocytic atypia are very much distinctive in $\mathrm{H} \& \mathrm{E}$ stain. According to 
Koss et al. Koilocytic atypia is sometime associated with carcinoma in situ and squamous cell carcinoma. In our study, most of the CIN lesions are associated with koilocytic atypia which indicate the presence of HPV infection, but could not be confirmed by DNA hybridization due to high cost.

Chronic cervicitis is a common pathological condition in adult female ${ }^{15}$. In this study. 21 cases $(33.3 \%)$ were diagnosed as chronic cervicitis. Majority of these cases were associated with squamous metaplasia as squamous metaplasia is a sequelae of chronic cervicitis. Though chronic cervicitis is mostly asymptomatic, but it is important because it may lead to pelvic inflammatory disease. Chronic cervicitis may also play a role in the initiation and promotion of cervical intraepithelial neoplasia ${ }^{15}$.

Papanicolaou smear is highly sensitive to cervical cancer. On the other hand the Pap smear has several limitations also. To interpret the Pap smear require skilled pathologist especially cytopathologist. In Bangladesh cytopathologist are few in number to give the optimum service to a large population. Most papanicolaou smear abnormality which do not signify a serious precancerous or cancerous condition, require lengthy follow-up procedure and large number of patients are lost in this process. Thus, it is assumed that VIA test will be an effective alternative of Pap smear to screen women for CIN lesions. It is cost effective and do not require highly skilled persons.

\section{Conclusion}

In conclusion it appears that majority of the colposcopically negative VIA positive cases are the patients of chronic cervicitis. However, colposcopic examination of VIA positive cases can detect most of the cervical intraepithelial lesions. So further study involving large number of VIA positive cases with case control study is essential.

\section{References}

1. Rohan ET, Robert DB, Eduaro LF. Toward a reduction of the global burden of cervical cancer. American Journal of Obstetrics and Gaynaecology 2003;189: 37-39.

2. Ashrafunnessa KS, Samsuddin L, Rahman AJE, Kamal M, Kabir S. Cervical dysplasia among women attending gynaecology outpatient department of a teaching hospital, BJMS, 2002; 8(1):39-42.
3. Rosai J. Female reproductive system, in Ackerman's Surgical pathology, 9th edition, Mosby Company, St Louis, 2004; 1523-1551.

4. Olaniyan OB. Validity of colposcopy in the diagnosis of early cervical neoplasia: a review. African journal of reproductive health. 2002:59-69

5. Sahu B, Latheef R, Magd SA. Prevalence of pathology in women attending colposcopy for postcoital bleeding with negative cytology. Archives of gynecology and obstetrics. 2007;276(5):471-3.

6. Dalla Palma P, Rossi PG, Collina G, Buccoliero AM, Ghiringhello B, Lestani M, Onnis G, Aldovini D, Galanti G, Casadei G, Aldi M. The risk of false-positive histology according to the reason for colposcopy referral in cervical cancer screening: a blind revision of all histologic lesions found in the NTCC trial. American journal of clinical pathology. 2008;129(1):75-80.

7. Adams AL, Eltoum I, Roberson J, Chen J, Connolly K, Chhieng DC. Negative colposcopic biopsy after positive human papilloma virus (HPV) DNA testing: false-positive HPV results or false-negative histologic findings?. American journal of clinical pathology. 2006;125(3):413-8.

8. Pretorius RG, Zhang WH, Belinson JL, Huang MN, Wu LY, Zhang X, Qiao YL. Colposcopically directed biopsy, random cervical biopsy, and endocervical curettage in the diagnosis of cervical intraepithelial neoplasia II or worse. American journal of obstetrics and gynecology. 2004;191(2):430-4.

9. Zuchna C, Hager M, Tringler B, Georgoulopoulos A Ciresa-Koenig A, Volgger B, Widschwendter A, Staudach A. Diagnostic accuracy of guided cervical biopsies: a prospective multicenter study comparing the histopathology of simultaneous biopsy and cone specimen. American journal of obstetrics and gynecology. 2010;203(4):321-e1.

10. Gage JC, Hanson VW, Abbey K, Dippery S, Gardner S, Kubota J, Schiffman M, Solomon D, Jeronimo J. Number of cervical biopsies and sensitivity of colposcopy. Obstetrics \& Gynecology. 2006;108(2):264-72.

11. Boicea A, Patrascu A, Surlin V, Iliescu D, Schenker M, Chiutu L. Correlations between colposcopy and histologic results from colposcopically directed biopsy in cervical precancerous lesions. Rom J Morphol Embryol. 2012;53(3 Suppl):735-41

12. Underwood M, Arbyn M, Parry-Smith W, De Bellis-Ayres S, Todd R, Redman CW, Moss EL. Accuracy of colposcopy-directed punch biopsies: a systematic review and meta-analysis. BJOG: An International Journal of Obstetrics \& Gynaecology. 2012; 119(11):1293-301.

13. Duesing N, Schwarz J, Choschzick M, Jaenicke F, Gieseking F, Issa R, Mahner S, Woelber L. Assessment of cervical intraepithelial neoplasia (CIN) with colposcopic biopsy and efficacy of loop electrosurgical excision procedure (LEEP). Archives of gynecology and obstetrics. 2012;286(6):1549-54

14. Seshasdri L, Jairaj P, Krisnaswami H. Colposcopy in the diagnosis of cervical neoplasia, Indian Journal of cancer 1990;27: 180-186

15. Soutter W, Butler J, Tipples M. The role of colposcopy in the follow up of women treated for cervical intraepithelial neoplasia. British Journal of Obstetrics and Gynaecology 2006;113:511-514 